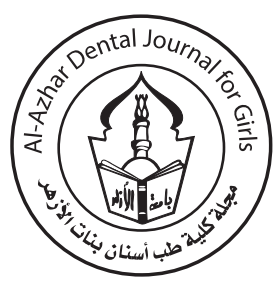

\title{
Comparative Study of Implant Supported Overdenture Retained with Two Types of Attachments
}

\author{
Sarah Ali Ashour Elqady ${ }^{(1)}$, Amany Ahmed Abd El-Fatah ${ }^{(2)}$ and Nesreen Ahmed El-Mahrouky ${ }^{(3)}$
}

Codex : 06/1801

azhardentj@azhar.edu.eg

http://adjg.journals.ekb.eg

\section{KEYWORDS}

Implant overdenture attachment

\begin{abstract}
Objectives: This study was conducted to compare implant retained mandibular overdenture with two different attachments (ball and socket and locator). Subject and methods:7 edentulous patients were selected according to certain criteria. Each patient received two platform switched implants placed in the mandibular canine-premolar region bilaterally. GROUP I: Locator attachments were used to retain the implant-supported overdentures. Locator abutments were loaded after 2-3 months. All patients received conventional maxillary dentures. After follow up periods we removed the attachment with wash period 1 month then we used ball and socket attachment GROUP II. The two groups were evaluated for retention, masticatory efficiency and EMG at 0,3 and 6 months after loading of each attachment. Results: regarding the effect of time on retention of both groups in ball group there was a significant increase in retention at base line till 3 months and decrease from 3-6 months, while locator group there was increase of retention through all periods. Regarding the effect of time on both groups the masticatory efficiency of both ball and locator group have no significant difference through all periods. Comparing the two groups the masticatory efficiency has no significant difference except on chewing carrots the numbers of strokes till first swallow increase in ball group, and on chewing peanut after 6 months the ball group show higher time till first swallow than locator as well as the time to empty mouth. Regarding the effect of time on both groups the electromyographic activity of both masseter and temporalis muscles has no significant difference through all periods except in locator group decrease the activity of masseter after 3 months. Conclusions: the ball attachment at the beginning has a higher retention quality than locator attachment, by time ball attachment loss some of its retention rather than locator attachment. The electromyographic activities and the masticatory efficiency of temporalis and masseter muscles of both ball attachment and locator attachment were comparable.
\end{abstract}

1. Post graduate student, Department of Removable Prosthodontics, Faculty of Dental Medicine, El -Azhar University, for girls.

2. Professor of Prosthodontics, the Vice Dean of Faculty of Dental Medicine, El-Azhar University, for girls.

3. Professor of Prosthodontics, the head of prosthodontic Dept., Faculty of Dental Medicine, El-Azhar University, for girls. 


\section{INTRODUCTION}

Many edentulous patients wearing conventional complete dentures are unsatisfied with their prosthesis. This is particularly common with mandibular dentures, because of their smaller denture bearing area, unfavorable distribution of occlusal forces resulting in increased rate of bone resorption, decreased stability and retention, pain as well as patients' discomfort.

A severely resorbed ridge makes ideal denture fabrication a difficult task. The difficulty is compounded in the mandible due to mobile structures like tongue and cheeks in the proximity which tend to dislodge the denture more in absence of adequate support from the edentulous ridge. The advent of implants has brought forth numerous options for complete denture fabrication even in the absence of adequate support and retention from the ridge ${ }^{(1)}$.

The use of implants in elderly completely edentulous patients, who request better stabilization of the mandibular denture, is now well documented. In addition to the advantages offered by conventional tooth supported overdentures, implants have the benefit of offering more predictable results. Implants could be used in completely edentulous patients in conjunction- with attachments to enhance the retention and stability of the overdenture. Many types of attachments have been used to augment the retention and stability of an implant overdenture. Many types of attachments could be used to retain these overdentures to the implants. Ball and socket attachments were the simplest ones, that offered high wear resistance and provided additional stability, retention and support The locator system offers clinicians an attachment with many advantages as an extremely low profile, a self-aligning feature which, dual retention feature, long-lasting durability and accommodation for divergent implants. ${ }^{(2)}$

However, studies comparing between ball and socket attachments and locator attachment to be still required. This study was, therefore performed to evaluate the masticatory efficiency of the implants supporting a mandibular overdenture and the retention in both types of attachments.

\section{SUBJECTS AND METHODS}

Seven completely edentulous male patients, age ranging from 40-60 years (average of 55.3 years) were selected from the Outpatient Clinic of the Prosthodontic Department; Faculty of Dental Medicine, Al- Azhar University, for girls according to certain criteria. All selected patients were informed of the nature of this research work. Only motivated patients who showed co-operation participated in the study after signing an informed consent.

A radiographic template was constructed with two metal balls at the canine regions. Radiographic assessment was performed using cone beam computed tomography (CBCT). The CBCT scans were taken using Scanora 3D. CBCT scans were taken while the patients wore their radiographic templates. Bone height, density and the buccolingual width at the proposed implant sites were measured and assessed. For all selected patients maxillary and mandibular conventional complete dentures were constructed before the surgical procedures for implant placement in the usual manner following the standard protocol of the Prosthodontic Department.

\section{Surgical procedures}

Implant system used: Legacy screw vent implants (Implant Direct LLC.CA.U.S.A) $13 \mathrm{~mm}$ in length and $3.7 \mathrm{~mm}$ (body diameter), $3.5 \mathrm{~mm}$ (platform switching diameter) were used. The implants are characterized by having mini - threads \{textured by blasting with SBM (Soluble Blast Media) of Hydroxyapatite crystals or HA-coated (High Crystalline layer)\}, an internal connection with a $2 \mathrm{~mm}$ long hex and an external bevel.

The metal balls were removed from the radiographic template and holes were drilled at the proposed implant sites (canine region) to be used as a surgical stent. 
Phase I surgical procedure: Implant installation was carried out guided by the surgical stent.

Phase II prosthetic procedure: Second stage surgery was carried out four months after implant placement. Surgical stent was used to relocate implant sites under infiltration anesthesia. A punch of $4.2 \mathrm{~mm}$ was used to punch the mucosa over the implants. The Locator implant attachment system (Implant Direct LLC.CA.U.S.A ) was used in this study. Cover screws were removed and the locator abutments were screwed onto the implants this was considered as (Group I) (Fig. 1).

New dentures were constructed for the patients in this group. Impressions of the mandibular and maxillary arches were made and poured for construction of special trays. A maxillary final impression was made as usual. As for the mandibular arch, locator impression copings with the black processing males were first placed onto the locator abutments. A full arch final impression was then made using rubber base impression material. After complete setting and removal of the impression, locator implant analogs were then snapped onto the impression copings. The impression was poured to fabricate the working cast. On the obtained cast, the white Block-Out Spacers were snapped over the head of the implant analogs. The metal housings with their corresponding black processing caps were then snapped onto the implant analogues. Occlusion blocks were constructed on the maxillary master cast and mandibular working cast. This was followed by jaw relation registration and setting up of artificial teeth. The trial dentures were then tried inside the patients' mouth and any necessary adjustments were made. Waxing up of the trial dentures was then completed (with a standard denture base thickness of $1.5 \mathrm{~mm}$ ). After the wax elimination procedure the maxillary and mandibular dentures were processed into conventional heat cured acrylic resin as usual. Finishing and polishing of the dentures were performed and final adjustments were carried out after trying the overdenture inside the patient's mouth.

Follow-up periods for all patients in were assigned to be at the time of denture insertion, three months and six months following overdenture insertion.

After six months the locator attachments were removed using hex instruments and the cover screws were used again for one month (rest period).

\section{Group II}

After one month the cover screws were then removed by the aid of a hex instrument. The ball abutments were screwed on the implant, this group was considered as group II.

The lower denture was modified to receive the housing of the ball attachment by direct pick-up using self-cure acrylic resin after removing of locator housing from the fitting surface of the denture.

Follow-up periods for all patients in were assigned to be at the time of denture insertion, three months and six months following overdenture insertion.

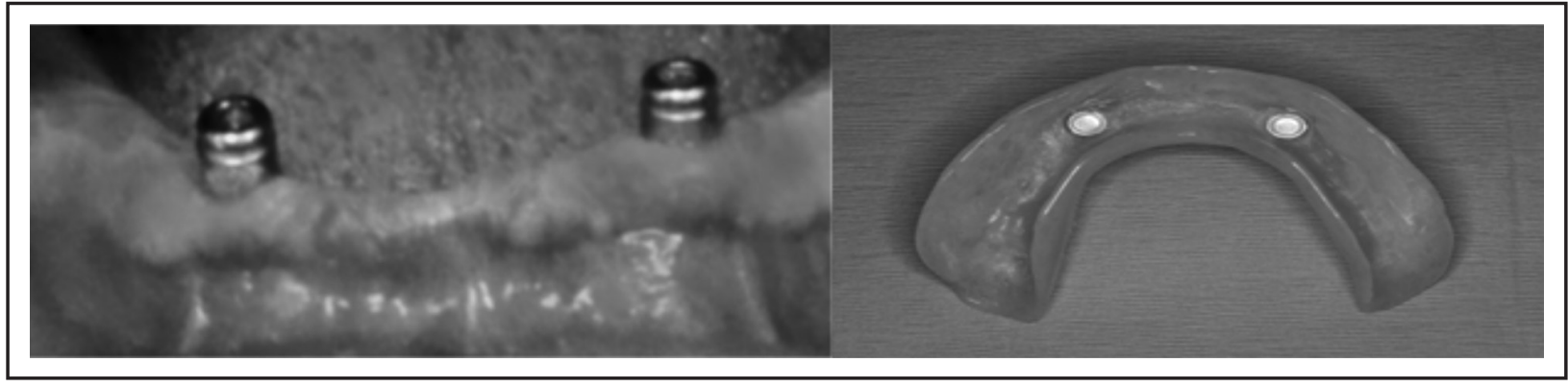

Fig. (1) The locator abutments and the picked up metallic housings and white retentive caps. 


\section{Evaluation of denture retention}

Retention was measured by Universal Testing Machine* which uses a computer software package to deliver a vertical dislodging force at a cross-head speed of $10 \mathrm{~mm} / \mathrm{min}$ to each denture sample from the vertical direction. The retentive forces required to separate the acrylic resin denture were measured after one, three months and six months from the delivered over denture of the group 1 and repeat this evaluation for the group 2 and the applied force was expressed in Newton(N).

The retention device's system is able to storing up to 600 test results from a choice of 10 programmable test set-ups. A range of highly accurate, identical load cells are available for tension, compression and cycling through zero force measurement.

The retention device composed of:

1- Attachment part: It is specially designed for this test and consists of two metallic arms perpendicular on each other. The vertical one can slide on the horizontal one through a metallic tube.

Vertical arm helps firm support of the chin during measuring the retention. The metallic tube is firmly attached to the horizontal arm by a tightening screw. Releasing these tightening screws permits forward and backward movement of a horizontal arm along the vertical arm.

The horizontal arm consists of metallic rod (30 $\mathrm{cm}$ length and $8 \mathrm{~mm}$ diameter) and at the end of this rod there is a small metallic arch like bow containing two small pins which retained the denture firmly during vertical movement on the universal testing machine. The metallic pins are adjusted to be nearly in the premolar region for denture from the buccal aspect.

2- Chin rest: It is composed of adjustable rigid metallic rest (triangular in shape) with a heavy weight base $(10 \mathrm{~cm}, 1.5 \mathrm{~cm}$ thickness) and a vertical arm to help firm support of the chin during measuring the retention. 3-Universal Testing Machine: This is the device that allows applying an increasing vertical upward force on the denture.

\section{Method for measuring retention:}

1. The patient was instructed to sit in an upright position and keep his chin firmly seated on a chin support. The bar was rigidly connected to the denture and the attachment part of the universal machine was adjusted.

2. A vertical dislodging force was applied by the universal testing machine.

3. The force was increased gradually in a vertical direction until dislodgement of the denture occurred.

4. The upper plate of the machine included the universal arm of specially designed retention measuring device. The device was subjected to a slowly increasing vertical load $(10 \mathrm{~mm} / \mathrm{min})$ until the denture was totally out of place. The load at dislodgement manifested by an audible sound tuck and confirmed by a sharp drop at load-deflection curve recorded using computer software (nexygen-MT-4.6; LIoyd instruments) and this value was recorded in Newton.

5. The test was repeated five times to obtain 5 records, the mean of which was calculated. This test was performed for each denture after one month and three months and six months from delivery. This period allowed for tissue rebound.

The retention force mean values obtained were recorded, tabulated and statistically analyzed for each group.

\section{Electro Myographic evaluation:-}

Electromyographic recording was done using an electromyographic device* which has the following components:

\footnotetext{
* Model LRX-Plus, Lloyd Instruments, Fareham, UK
} 
1. Stimulating unit: which stimulating electrodes were connected.

2. Recording unit with amplifier: which recording and ground electrodes were connected. The amplifier used in this study had four channel terminals.

3. Electrodes: ground bracelet electrode, bipolar stimulating electrode, two surfacemetal recording electrodes and two ring electrodes.

\section{The following procedures were carried out for each patient in (groupI)}

The patient was seated relaxed in a comfortable chair with the head erect and it has been assured that his head level remains constant during the recording procedure. The skin was thoroughly cleaned using alcohol. The cleaning involved all points that were to be used as recording, stimulating or grounding points. Conducting gel was also applied on the surface recording electrodes. The position of the surface and reference electrodes was determined by palpation on the main direction of muscle fibers after asking the patient to clench on his teeth. The most contractile and palpable fibers of superficial masseter and anterior temporalis muscles were located.

\section{Record for the Right Temporalis Muscle:}

The surface and reference electrodes were filled with conductive gel and then placed on the skin covering the anterior fibers of the right temporalis muscle (as predetermined from the last step) and fixed with adhesive strips.

The exact site of the electrodes (surface and reference electrodes) was marked on a plastic transparent template. This mark was done in relation to anatomical reference points as the nose, external auditory meatus, eye brows and the corner of the mouth.

The soft test food (banana) was cut into one centimeter equal sized pieces. The patient was instructed to place one piece per time in the right side and chew it, and then the electromyographic activity was recorded. The same procedure was repeated with the fibrous test food (carrot) and hard test food (peanut) to record the electromyographic activity. Five readings of the amplitude of each electromyographic recording were recorded and then the mean amplitude was calculated. The same steps were repeated for the left temporalis, right masseter and left masseter muscles.

The same steps were repeated after three month and six months for group I and group II after changing the attachment after one month ,three months and six months.

The data obtained were recorded, tabulated and statistically analyzed for each group.

\section{Evaluation of Masticatory efficiency:}

The masticatory efficiency was evaluated after one month from the retained overdenture delivery for two groups. Five measures were recorded while patients were chewing standardized pieces of one $\mathrm{cm}$ of banana and carrot and one grain of peanuts. These food represented soft, fibrous and hard crushable food, respectively.

Five measurements were recorded during chewing food specimen as follow:

a) The number of chewing strokes up to the first swallows.

b) The number of chewing strokes until mouth free of food.

c) The number of swallowing until mouth free of food.

d) The time (in second) elapsed until the first swallow.

e) The time (in second) elapsed until the mouth was free of food.

Two observers who remained the same throughout the study recorded the measurements, one recorded the number of chewing strokes and swallowing, and the other recorded the time. Patient 
was seated in an upright position and instructed to chew food at normal rate and swallow at increments.

Patient was observed and asked about preferred and non-preferred. These steps were repeated in group I for one month, three months and six months and were repeated for the group II for one month, three months and six months.

The data obtained were recorded, tabulated and statistically analyzed for each group.

\section{RESULTS}

\section{Retention}

\section{Effect of time}

As regards Ball and Socket attachment, there was a statistically significant increase in mean retention values after 3 months. From 3 months to 6 months, there was a statistically significant decrease in mean retention values. However, the mean retention values after 6 months showed statistically significantly higher mean value than base line measurement.

While for Locator attachment, there was a statistically significant increase in mean retention values after 3 months as well as from 3 months to 6 months.

\section{Comparison between types of attachments}

There was no statistically significant difference between mean retention values in the two groups at base line and after 3 months. After 6 month; Ball and Socket attachment showed statistically significantly lower mean retention values than Locator attachment

\section{Masticatory efficienc}

\section{A. Number of strokes till first swallow \\ 1-Effect of time}

On chewing Banana or Peanuts either with Ball and Socket or Locator attachments, there was no statistically significant change in mean number of strokes till first swallow through all periods.
On chewing Carrots with Ball and Socket attachment, there was no statistically significant change in mean number of strokes till first swallow after 3 months. From 3 months to 6 months, there was a statistically significant increase in mean number of strokes till first swallow. While with Locator attachment, there was no statistically significant change in mean number of strokes till first swallow through all periods.

\section{Comparison between types of attachments}

On chewing either banana or carrots; there was no statistically significant difference between mean numbers of strokes till first swallow in the two groups at base line and after 3 months. After 6 month; Ball and Socket attachment showed statistically significantly higher mean numbers of strokes till first swallow than Locator attachment.

While on chewing Peanuts; there was no statistically significant difference between mean numbers of strokes till first swallow in the two groups at base line, after 3 as well as 6 months.

Table (1): Mean, standard deviation (SD) values and results of two-way repeated measures ANOVA test for comparison between number of strokes till first swallow with the two types of attachment

\begin{tabular}{|c|c|c|c|c|c|c|}
\hline \multirow{2}{*}{ Food type } & \multirow{2}{*}{ Time } & \multicolumn{2}{|c|}{$\begin{array}{l}\text { Ball \& } \\
\text { Socket }\end{array}$} & \multicolumn{2}{|c|}{ Locator } & \multirow{2}{*}{$P$-value } \\
\hline & & Mean & $\mathrm{SD}$ & Mean & $\mathrm{SD}$ & \\
\hline \multirow{3}{*}{ Banana } & Base line & 18.6 & 1.7 & 18.0 & 2.1 & 0.208 \\
\hline & $3 \mathrm{~m}$ & 18.6 & 1.7 & 18.0 & 2.1 & 0.208 \\
\hline & $6 \mathrm{~m}$ & 18.8 & 2.5 & 17.6 & 2.3 & $0.033 *$ \\
\hline \multirow{3}{*}{ Peanuts } & Base line & 19.4 & 2.4 & 19.2 & 2.3 & 0.163 \\
\hline & $3 \mathrm{~m}$ & 19.6 & 2.1 & 19.2 & 2.3 & 0.143 \\
\hline & $6 \mathrm{~m}$ & 20.4 & 2.7 & 18.8 & 2.6 & 0.067 \\
\hline \multirow{3}{*}{ Carrots } & Base line & 26.0 & 5.2 & 24.0 & 4.8 & 0.189 \\
\hline & $3 \mathrm{~m}$ & 26.8 & 5.7 & 23.8 & 5.2 & 0.095 \\
\hline & $6 \mathrm{~m}$ & 28.2 & 5.4 & 23.2 & 5.4 & $0.038 *$ \\
\hline
\end{tabular}

*: Significant at $P \leq 0.05$ 


\section{B. Number of strokes to empty mouth}

\section{Effect of time}

On chewing Banana, Peanuts and Carrots either with Ball and Socket or Locator attachments, there was no statistically significant change in mean number of strokes to empty mouth through all periods.

\section{Comparison between types of attachments}

On chewing either banana or carrots there was no statistically significant difference between mean numbers of strokes to empty mouth in the two groups at base line and after 3 months. After 6 month; Ball and Socket attachment showed statistically significantly higher mean numbers of strokes to empty mouth than Locator attachment. While on chewing Peanuts; there was no statistically significant difference between mean numbers of strokes to empty mouth in the two groups at base line, after 3 as well as 6 months.

\section{B. Number of swallows to empty mouth}

\section{Effect of time}

On chewing Banana, Peanuts, Carrots either with Ball and Socket or Locator attachments, there was no statistically significant change in mean number of swallows to empty mouth through all periods.

\section{Comparison between types of attachment}

On chewing Banana, Peanuts or carrots; there was no statistically significant difference between mean numbers of swallows to empty mouth in the two groups at base line, after 3 as well as 6 months

\section{Time till first swallow}

\section{Effect of time}

On chewing Banana, Peanuts and Carrots either with Ball and Socket or Locator attachments, there was no statistically significant change in mean time till first swallow through all periods.

\section{Comparison between types of attachments}

On chewing either Banana or Carrots; there was no statistically significant difference between mean time till first swallow in the two groups at base line, after 3 as well as 6 months.

While on chewing Peanuts; there was no statistically significant difference between mean time till first swallow in the two groups at base line and after 3 months. After 6 months, Ball and Socket group showed statistically significantly higher mean time till first swallow than Locator group.

\section{Time to empty mouth}

\section{Effect of time}

On chewing Banana, Peanuts, and Carrots either with Ball and Socket or Locator attachments, there was no statistically significant change in mean time to empty mouth through all periods.

\section{Comparison between types of attachments}

On chewing Banana; there was no statistically significant difference between mean time to empty mouth in the two groups at base line and after 3 months. After 6 months, Ball and Socket group showed statistically significantly higher mean time to empty mouth than Locator group.

On chewing Peanuts; there was no statistically significant difference between mean time to empty mouth in the two groups at base line and after 6 months. After 3 months, Ball and Socket group showed statistically significantly higher mean time to empty mouth than Locator group.

While on chewing Carrots; there was no statistically significant difference between mean time to empty mouth in the two groups at base line, after 3 as well as 6 months.

\section{Electromyographic activities (EMG)}

\section{A. Masseter muscle}

\section{Effect of time}

On chewing Banana or Peanuts either with Ball and Socket or Locator attachments, there was no statistically significant change in mean Masseter muscle activity through all periods. 
Table (2): Mean, standard deviation (SD) values and results of two-way repeated measures ANOVA test for comparison between Masseter muscle activity at different time periods within each type of attachment

\begin{tabular}{|c|c|c|c|c|c|c|c|c|}
\hline \multirow{2}{*}{ Food type } & \multirow{2}{*}{$\begin{array}{l}\text { Attachment } \\
\text { type }\end{array}$} & \multicolumn{2}{|c|}{ Base line } & \multicolumn{2}{|c|}{3 months } & \multicolumn{2}{|c|}{6 months } & \multirow{2}{*}{$P$-value } \\
\hline & & Mean & $\mathrm{SD}$ & Mean & $\mathrm{SD}$ & Mean & $\mathrm{SD}$ & \\
\hline \multirow{2}{*}{ Banana } & Ball \& Socket & 597.66 & 106.58 & 603.29 & 71.43 & 629.01 & 213.95 & 0.784 \\
\hline & Locator & 576.29 & 81.34 & 610.27 & 76.52 & 612.08 & 197.54 & 0.233 \\
\hline \multirow{2}{*}{ Peanut } & Ball \& Socket & 561.04 & 27.45 & 587.10 & 57.46 & 599.62 & 43.46 & 0.315 \\
\hline & Locator & 562.54 & 27.13 & 586.95 & 65.64 & 574.32 & 37.10 & 0.688 \\
\hline \multirow{2}{*}{ Carrots } & Ball \& Socket & 558.20 & 16.76 & 549.10 & 35.92 & 512.53 & 71.81 & 0.606 \\
\hline & Locator & $550.39^{\mathrm{A}}$ & 17.98 & $556.40^{\mathrm{A}}$ & 25.61 & $499.73^{\text {в }}$ & 65.23 & $0.021 *$ \\
\hline
\end{tabular}

*: Significant at $P \leq 0.05$, Different superscripts in the same row are

On chewing Carrots with Ball and Socket attachment, there was no statistically significant change in mean Masseter muscle activity through all periods. While with Locator attachment, there was no statistically significant change in mean Masseter muscle activity after 3 months. From 3 months to 6 months, there was a statistically significant decrease in mean Masseter muscle activity.

\section{Comparison between types of attachments}

On chewing Banana, Peanuts or Carrots; there was no statistically significant difference between Masseter muscle activities in the two groups at base line, after 3 as well as 6 months

\section{B. Temporalis muscle}

\section{1- Effect of time}

On chewing Banana, Peanuts or Carrots either with Ball and Socket or Locator attachments, there was no statistically significant change in mean Temporalis muscle activity through all periods.

\section{2- Comparison between types of attachments}

On chewing Banana, Peanuts or Carrots; there was no statistically significant difference between Temporalis muscle activities in the two groups at base line, after 3 as well as 6 months.

\section{DISCUSSION}

All patients participated in this study were satisfied with their implant retained overdentures. This may be attributed to the enhanced retention and improved stability of the mandibular dentures after attachments installation.

In the present study, the ball attachments showed significantly higher retention characteristics than locator attachments. This has been augmented by many authers, who reported that the retention from ball attachment is high in comparison to other attachment ${ }^{(3)}$. They attributed this finding to the frictional fit of the female part which is incorporated in the fitting surface of the denture in a snap like action on the metal ball (male portion) which is screwed into the fixture when the overdenture is inserted. Also, the ball is attached to a post with a groove or undercut area which provides highest score of retention to the overdenture. ${ }^{(4)}$

Many authors agree that for un-splinted implants, the most common attachment used is the ball attachment, as this attachment system is a practical, effective, and relatively low $\operatorname{cost}^{(5)}$, also comparing denture stability in mandibular implant retained overdenture using ball, magnet, or bar attachment, revealed that the use of ball attachment was advantageous in regards to minimizing denture movement ${ }^{(6,7)}$. 
Ball attachment group showed significant decrease in there retention values throughout the follow up period. This could be attributed with the results of some studies have found that the wear of components of ball attachment was responsible for a decrease in the initial retentive force of ball attachments $32-50 \%{ }^{(8,9)}$. Some studies revealed that most of the attachment system showed a common trend toward a reduction or total loss in their retentive forces. Moreover, repeated insertion-removal cycles led to a gradual and continuous loss of retention of ball-socket attachment should be repeated annually or biannually by the clinician ${ }^{(10)}$.

After 3-years of prospective study for implant mandibular supported overdenture either retained with ball, bar, or telescopic attachments, it was found that the implant success and peri-implant condition did not differ between attachments, but the ball attachment showed significantly higher frequency of technical complication than that of telescopic and bar attachment in implant supported overdenture $^{(11)}$.

In this study the high retentive values that were observed in ball attachment group when compared with locator attachment group may be attributed to the difference in the abutment design configuration of both attachments. In case of ball attachment the abutment connected to the implant is the male part which has a groove or undercut through which the female part snaps on and attaches firmly to the abutment. While in case of locator attachment group provides dual retention internal retention and external retention. This may be explaining the reduction in retention values in ball attachment rather than locator attachment by time ${ }^{(12,13)}$.

Attributed to the fact that ball-socket and locator attachments are considered to be resilient attachment which allows some degree of rotation movement during function and less force directed to the implant rather than the rigid attachment as bar attachment which has higher retentive force. The more retentive attachment allowing better chewing ability and comfort to the patients resulting in better electromyographic activity results and masticatory efficiency ${ }^{(14)}$.

These results are in agreement with the finding of Van der Bilt A et al,2006 ${ }^{(15)}$ who demonstrated that the attachment type in implant supported mandibular overdenture had some influence on oral function. The maximum bite force generated by subjects with their mandibular overdenture attached to a ball attachment has been reported to be nonsignificantly difference than locator attachment. In addition Gomes et al, 2010(16) stated masticatory time dependent on several factors; beginning with the type of food. Masticatory time banana was shorter in ball attachment than for locator attachment. Carrot took significantly longer to chew for ball attachment than locator. Also the ball and socket recorded a higher masticatory time till mouth become free than locator.

The result of the present study, observed a nonsignificant difference in cycle duration between the two attachments, which agree with previous studies results. Thus, implant -support of the mandibular denture did not affect the chewing rate. The difference retentive capacities of the attachment used in our study had no noticeable effect on the cycle duration.

Finally according to previous studies, which demonstrate the relation between masticatory function and type of attachment. Bite force and masticatory performance were selected as variables that are often used in the objective evaluation of masticatory function.

On the other hand the results of this study may not completely agree with Rutkunas V et al, 2005 ${ }^{(17)}$, who stated that the type of attachment used does not seem to evoke major difference in maximum bite force. The clinical performance of the implant can be rated as excellent whatever various attachment systems were applied. 
However, the authors study that no such difference between different attachment types, either for chewing efficiency or for unilateral and bilateral bite force. It has been suggested that the provision of dental implant to subjective oral function to the level experienced by satisfied wearers of the conventional full dentures.

\section{CONCLUSIONS}

Within the limitations of this study, the following conclusions could be drawn:

1- Despite of, the ball attachment at the beginning has a higher retention quality than locator attachment, by time ball attachment loss some of its retention rather than locator attachment.

2- The electromyographic activities and the masticatory efficiency of temporalis and masseter muscles of both ball attachment and locator attachment were comparable.

\section{REFERENCES}

1. Timo O,Narhi M, Geertman HA et al.Changes in edentouls maxilla in persons wearing implant retained mandibular overdentures, J Prosthet Dent, 2010; 84(2):43-49 .

2. Emami E, Heydecke G, Rompré PH, de Grandmont $\mathrm{P}$, Feine JS. Impact of implant support for mandibular dentures on satisfaction, oral and general health-related quality of life: a meta-analysis of randomized-controlled trials. Clin Oral Implants Res. 2009 Jun; 20(6):533-44.

3. Sadig W. A comparative in vitro study on the retention and stability of implant-supported overdentures. Quintessence Int. 2009 Apr; 40(4):313-319.

4. Stevens PJ, Frederickson DJ, Gress ML. Implant Prosthodontics. Clinical and laboratory procedures; 2nd ; Mosby Inc: St. Louis, Missouri,2000.

5. Krennmair G, Weinlander M, Krainhofner M. Implantsupported mandibular overdentures retained with ball or telescopic crown attachments: a 3-year prospective study. Int J Prosthodont. 2006; 19: 164-170.
6. Han-Wool L, In- Ho C, Jong- Hyuk L, Yu-Sung C. A study on the changes in attractive force of magnetic attachments for overdentures. J Adv Prosthodont. 2016; 8: 9-15.

7. Winkler S, Piermatti J, Rothman A, Siamos G. An overview of the O-ring implants overdenture attachment. Clinical Reports. J Oral Implant. 2002; 28: 82-86.

8. Shastry T, Anupama NM, Shetty S, Nalinakshamma M. An in vitro comparative study to evaluate the retention of different attachment systems used in implant-retained overdentures. J Indian Prosthodont Soc. 2016; 16:159-166.

9. Freeman C, Brook I, Joshi R. Long- term follow-up of implant- stabilized overdentures. Eur J Prosthodont Restor Dent. 2001; 9: 147-150.

10. Parsa A, Mohammad H, Leila Z, Samira A. The influence of implant angulations in one and two directions on the retentive properties of overdenture attachments: An in vitro study. J Indian Prosthodont Soc. 2014; 14: 72-77.

11. Tokuhisa M, Matsushita Y, Koyano K. In vitro study of mandibular implant overdenture retained with ball, magnet or bar attachment : comparison of load transfer and denture stability. Int J Prosthodont. 2003;16:128-34.

12. Gordon J. Christensen Clinicians Report.2011.

13. Saad A. Effect of two different attachments in implantsupported overdenture structures. M.D.S Thesis. Cairo University. 2013.

14. Amal MI. Evaluation of low- profile attachment for implant-retained mandibular overdentures in restoring cases with limited interarch space. Cairo Dent J. 2009; 25: 191-203.

15. Van der Bilt A, Van Kampen FM and Cune MS. Masticatory function with mandibular implant- supported overdentures fitted with different types of attachement. Eur J Oral Sci. 2006; 114:191-196.

16. Gomes SG, Custodio E, Foat F, Del Bel Cury AA and Garcia RC. Masticatory features, EMG activity and muscle effort of subjects with different facial patterns. $\mathrm{J}$ Oral Rehabil 2010;37:813-819.

17. Rutkunas V, Mizutani H, Takahashi H. Evaluation of stable retentive properties of overdenture attachment. Stomatologij, Baltic Dent Maxillofac J, 2005; 7:115 -120. 